\title{
SEISMIC DESIGN OF BRIDGES
}

\section{SECTION 11 \\ BRIDGES REQUIRING SPECIAL STUDIES}

\author{
M.J.N. Priestley*, P.R. Stanford**, A.J. Carr***
}

\subsection{GENERAL}

Some bridges, as a consequence of structural complexity, unusual ground conditions, or high cost or risk potential, merit special studies to better define seismic performance. To a large extent these categories have already been mentioned in other sections of this report on the seismic design of bridges. In particular, those bridges requiring consideration for dynamic analysis have been defined in section 10. This section attempts to identify special problems associated with specific situations and structural types, and where appropriate makes recommendations about suitable methods of analysis and detailing. The approach adopted is deliberately less formal than in previous sections, as the intention is more to bring possible problems to the attention of the designer than to present rigid design rules.

\subsection{SPECIAL STRUCTURAL TYPES}

Preceeding sections have concentrated on common New Zealand bridge types mainly structures supported on piers and abutments, where seismic response may be limited by plastic hinging of vertical elements, or simple spans either built monolithically with, or flexibly supported by, abutments. A number of less common structural types merit special consideration.

\subsubsection{Cable-supported Superstructures}

Suspension and cable-stayed bridges have structurally complex superstructures. Because of the tupically long spans involved, superstructures are relatively flexible both vertically and transversely. In assessing transverse and longitudinal seismic forces induced in superstructure elements or transmitted to supporting piers, realistic estimates of mode shapes, including consideration of flexibility of the superstructure, must be adopted. It is probable that as a result of high fundamental periods, response will be dominated by higher mode effects. As the superstructure will be designed to remain elastic during the design level earthquake, analysis may consist of an elastic modal analysis approach, with maximum response forces and displacements found from the square root of the sum of the squares (SRSS) of the individual modal maxima. However, under large amplitudes of vibration geometric non-linearity effects in both suspension and cablestayed bridges will tend to invalidate

* Reader in Civil Engineering, University of Canterbury, Christchurch

** Ministry of Works and Development, Wgtn

*** Senior Lecturer in Civil Engineering, University of Canterbury most modal techniques. Low damping can be expected from elastic response of continuous steel superstructures in the longitudinal and transverse directions (11.1, 11.2, 11.3). For analysis it is recommended that a value of $2 \%$ of critical damping be assumed.

In the vertical direction, cablestayed bridges may have high damping due to unequal cable lengths, and the nonlinear load-displacement characteristics of the bridge. If the displacements are of small amplitude and response essentially linear, then this large damping may not be apparent. Vertical response of suspension bridges in the higher modes may have low damping, and should be considered.

There is little information available on the ductility of such large elements as are commonly used for piers of cablesupported bridges. Consequently such piers should be designed for low ductility levels, or if possible, to remain elastic under the design-level earthquake. Because of large distances between major piers, large out-of-phase displacements may occur. Although the superstructure flexibility is likely to be such that these displacements can be easily accommodated, checking is necessary. Analyses should be based on a relative longitudinal or transverse displacement of adjacent major piers equal to twice the maximum response displacement $\Delta$ given by section 2 for the appropriate sêismic zone for a period of $3.0 \mathrm{~s}$. This corresponds roughly with the maximum expected relative free-field ground displacement.

The high capital value of cablesupported structures, and the severe consequences of major damage or collapse indicate that it will generally be appropriate to design for a low probability of occurrence of the design earthquake within the expected useful life of the structure.

\subsubsection{Arch Bridges}

It is difficult to detail arch bridges for ductility, and where possible, they should be designed to respond elastically to the design-level earthquake. A detailed structural analysis will be necessary to define longitudinal and transverse mode shapes. Seismic forces and displacements may be estimated using the SRSS method.

Special consideration must be given to relative longitudinal displacements of the arch springing due to out-of-phase ground motion and seismic response displacements of the typically steep embankments. Detailed geotechnical investigations should be carried out to establish the competence and stability of the embankments under seismic conditions. 


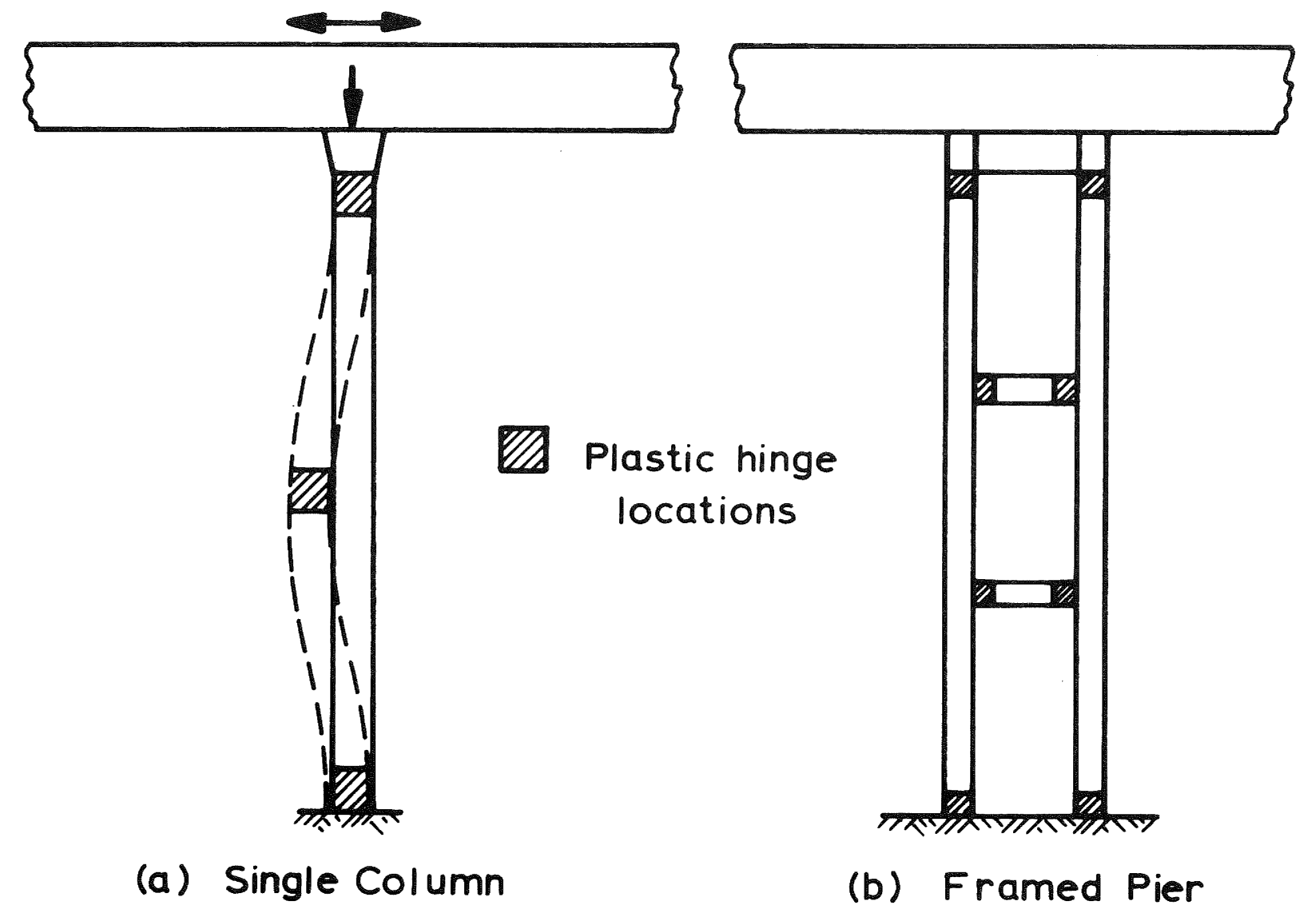

Fig 11-1 INERTIAL RESPONSE OF TALL SLENDER PIERS

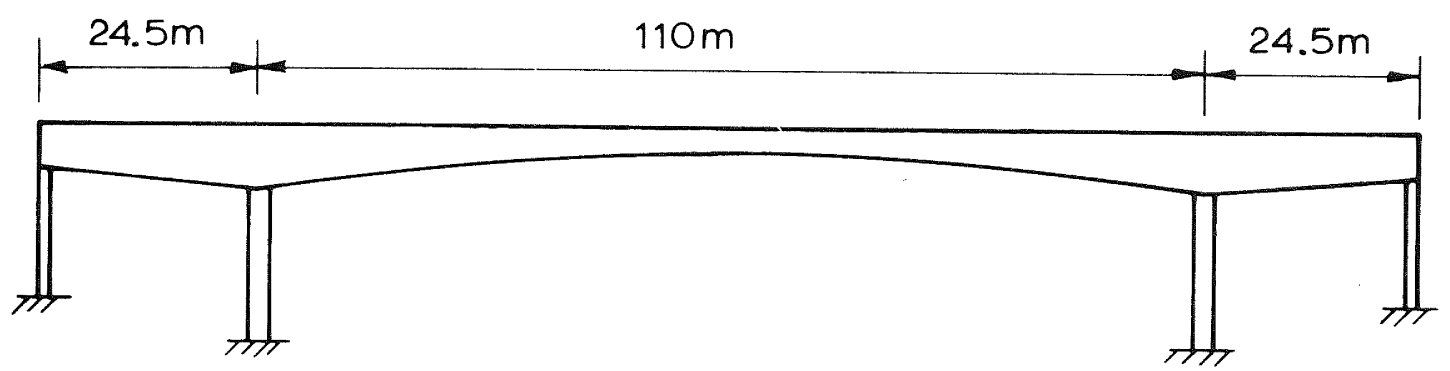

(a) Elevation

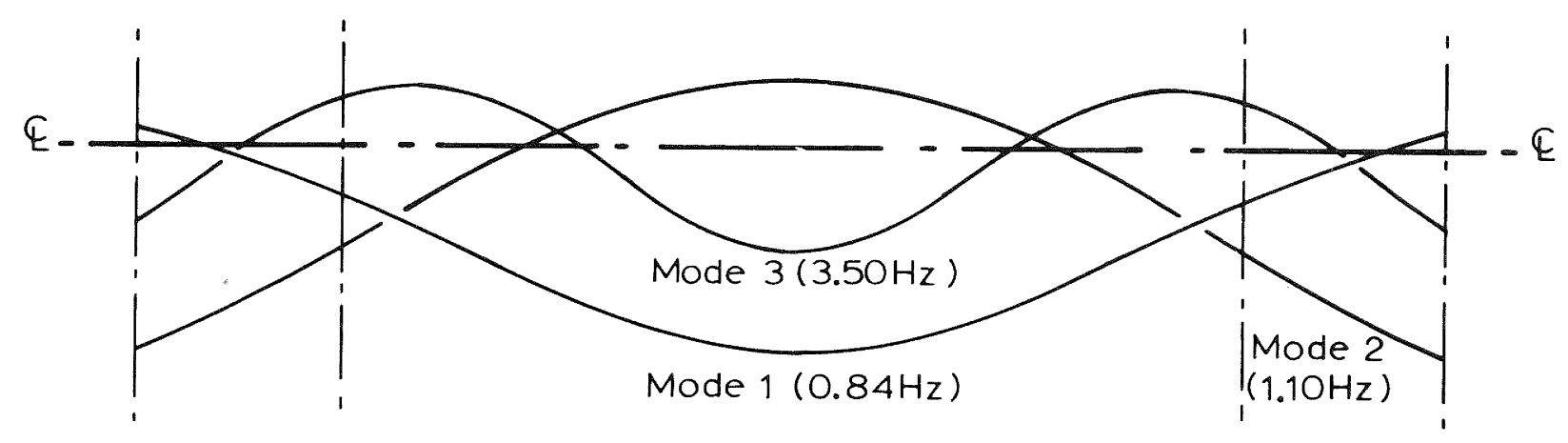

(b) Transverse Mode Shapes 
Two-pin or encastré arches will be less able to accommodate relative longitudinal displacements than three-pin arches.

\subsubsection{Stress-Ribbon Bridges}

It is unlikely that stress-ribbon construction will be used in New Zealand for other than minor structures, such as footbridges. Although there is little information available on the seismic performance of stress-ribbon bridges, it is expected that the inherent flexibility should result in satisfactory response. Horizontal forces and displacements should be based on realistic estimates of transverse and longitudinal mode shapes, including consideration of the superstructure flexibility.

\subsection{Bridges With Extreme Geometry}

Some bridges of conventional types merit special studies as a consequence of extreme height, length, width, skew or curvature.

\subsubsection{Bridges with Tall Piers}

Tall piers may be subjected to high inertia forces due to the response of the distributed mass of the pier itself. Ductility demands at intended plastic hinge locations may be substantially increased, and there may be a potential for plastic hinging to occur at a location close to mid-height, resulting in the formation of a collapse mechanism (see fig. 11-la). If preliminary analyses based on elastic response of distributed mass systems (e.g. ref. 11.4) indicate the possibility of such behaviour, the only realistic analysis will be a full dynamic inelastic time-history analysis of the pier/superstructure system. Tall piers should be checked for additional moments due to P- $\Delta$ effects. Results of such an analysis may be highly dependent on stiffness values assumed for the piers. A detailed assessment of stiffness variation up the column height should be made, identifying probable cracked and uncracked regions. Those regions subjected to significant cracking or possible yield should be assigned appropriate cracked-section stiffnesses. It may be necessary to carry out a sensitivity analysis to establish the significance of variation from assumed stiffness values to overall response.

It may be found necessary to reduce inertia response by using a framed pier system as shown in fig.ll-1b longitudinally and transversely.

If the superstructure of a bridge in this category is restrained transversely at abutments, bending of the superstructure in the horizontal plane may be critical as a result of large lateral displacements of the pier tops. Similarly, for single column piers, torsion of the superstructure may be critical as a result of rotation of the pier tops under lateral displacements.

\subsubsection{Bridges with Piers of Differing Heights}

When bridges span steep sided river valleys, substantial differences in adjacent pier heights may be inevitable. Where possible, flexibilities of piers should be adjusted to result in as uniform yield displacements and ductility demands on piers as possible. In some cases this may be effected by adjusting the flexibility of the supporting pile systems.

Where such attempts to 'regularise' the structural response are impractical, analyses must establish the realistic mass distribution to each pier, and how this is influenced by sequential, rather than simultaneous yielding of the separate piers, particularly in the longitudinal direction. For multispan bridges, transverse flexibility of the superstructure will generally become significant, particularly after initial yielding of some piers. Lateral forces transmitted back to abutments may be substantially different from those predicted by elastic analysis.

As an alternative to adjustment of pier flexibility, it may in some cases be easier to make all piers "stiff", and use energy dissipating devices to obtain ductility.

\subsubsection{Long-Span Bridges}

Transverse superstructure deformations may become significant in major bridges when the span/width ratio is large. This will particularly be the case for major rail bridges due to typically small widths. Mode shapes and forces induced in the support systems will be influenced by this flexibility, and superstructure plastic hinging may occur. Fig. 11-2 shows theoretical transverse mode shapes calculated for the North Rangitiki Rail Bridge on the North Island Main Trunk.

Analysis should at least be on the basis of a modal superposition approach, and dynamic inelastic time-history analysis is advisable to check ductility levels.

Response of the superstructure to vertical acceleration should be examined.

\subsubsection{Highly Skewed Bridges}

Examination of skewed bridges after recent earthquakes has established a tendency for rotation of the bridge centreline about a vertical axis towards the acute corners (see fig. 11-3). In the San Fernando earthquake of 1971 there were examples where this caused severe damage to columns, as a result of torsional shear forces, and to abutments, as a result of increased longitudinal displacements and inadequate seating lengthsli.5. Although there is some theoretical evidence to support this behaviourll.6 the mechanisms are not clearly understood. Consequently conservative assumptions should be made regarding necessary 


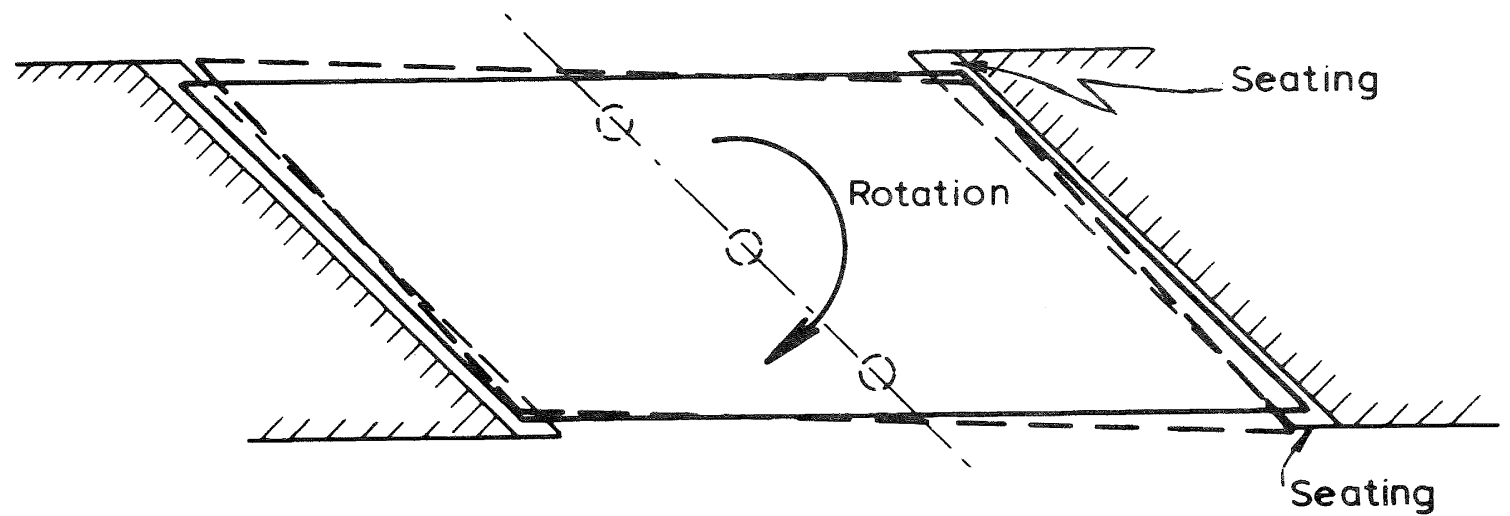

Fig.11-3 DIRECTION OF ROTATION OF SKEWED BRIDGE

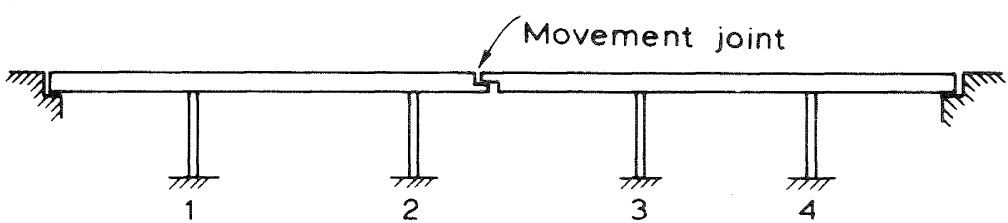

(a) Elevation

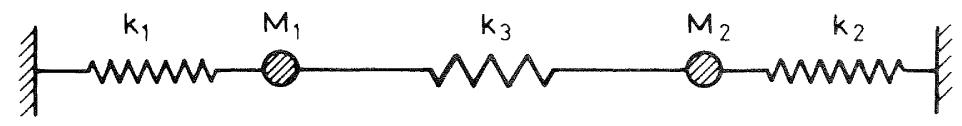

$k_{1}, k_{2}$ Stiffness of end bearings + piers

$k_{3}$ Stiffness of joint bearings + linkages

(b) Longitudinal Response

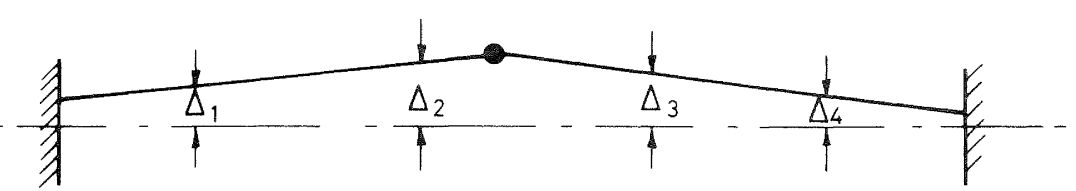

(c) Transverse Displacements

Fig.11-4 SEISMIC RESPONSE OF BRIDGE WITH MOVEMENT JOINT

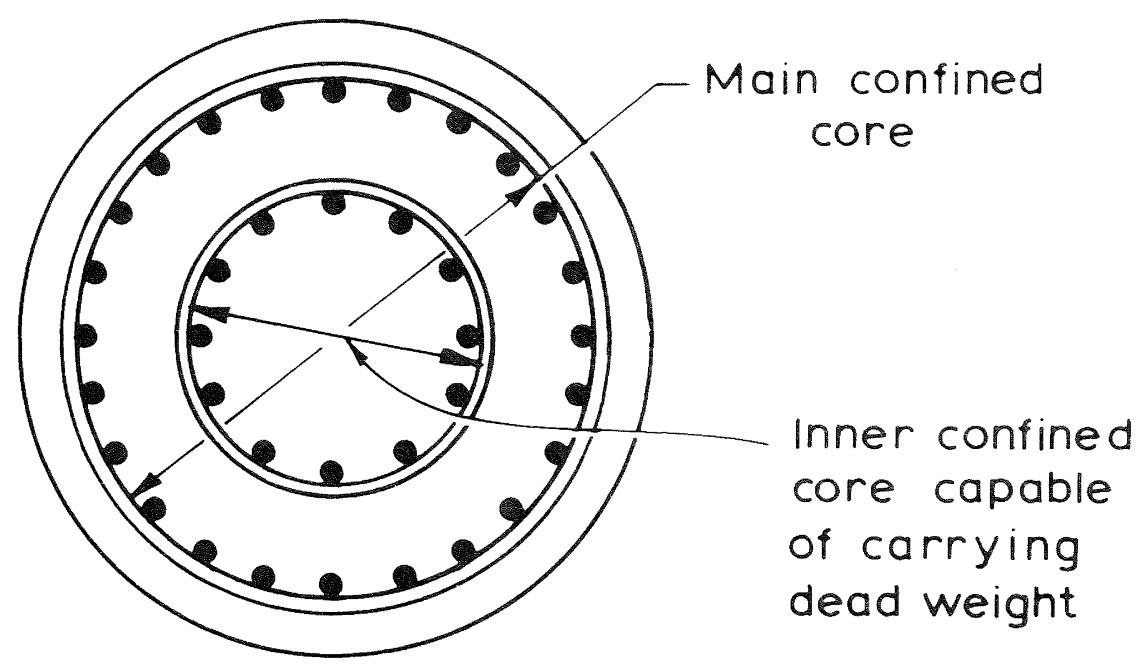

Fig.11-5 CIRCULAR BRIDGE COLUMN WITH INNER CONFINED CORE 
clearances, seating lengths and lateral restraint at abutments, and seismic shear forces induced in intermediate piers. To cope with torsional moments and increased flexural ductility demand, resulting from rotation about the vertical axis, conservative detailing should be specified, with an increase in the amount of confining steel above code requirements. It should be noted that this increase will be required over the full height of the columns, not just within potential plastic hinge zones.

\subsubsection{Bridges with Large Horizontal Curvature}

The seismic response of multispan bridges with large horizontal curvature and/or large horizontal deflection angle is difficult to predict with accuracy, particularly when the superstructure is torsionally stiff as will generally be the case to improve live-load distribution. Significant axial seismic forces may be induced in individual piers, even when each pier consists of a single column. Abutments may be subjected to high force levels. Hinging will occur at the top of single-column piers cast monolithic with the superstructure, at an early stage, even in the transverse direction.

The direction of relative movements or restraining forces at joints in the superstructure will be uncertain, and allowance for this should be made in detailing.

Analysis of curved multispan bridges ideally requires full 3-D inelastic analysis. As this will rarely be practical or even possible, conservative assumptions regarding forces in piers and required ductility demand must be made.

\subsubsection{Long Bridges with Internal Movement Joints}

The response of long bridge superstructures separated into two or more sections by internal movement joints can be difficult to predict. Out-ofphase ground movements, as well as structural differences between the separate sections may cause substantial relative movements across the movement joints.

For longitudinal response it will generally be conservative to assess seismic forces and ductility demands on columns by considering each section independently. Maximum fessible relative displacements at the movement joints could be obtained by considering peak displacements of the adjacent sections to be out of phase. However, a more realistic estimate of forces and relative longitudinal displacements may be obtained by modelling the movement joint s a spring system representing combined shear stiffness of bearings and axial stiffness of seismic linkage bolts, and analysing the coupled system. This approach is illustrated schematically in fig. $11-4 \mathrm{~b}$. An elastic modal super- position analysis should be sufficient to establish design forces and displacements. Out of phase ground movements at supports may add to relative displacements and should be considered.

The movement joint will act as a hinge for transverse seismic response. The resulting loss of stiffness to the superstructure may result in increased displacements, and hence increased ductility demand to piers on either side of the joint (fig. Il-4c). Realistic modelling of the articulation, of restraining forces at the joint provided by bearing and linkage stiffness, and possibility of impact associated with total joint closure, is necessary to ensure adequate prediction of transverse response. In some cases it may be desirable to make transverse response more regular by use of link spans, hinged at each end between abutments and main sections of the superstructure.

\subsubsection{Piers in Deep Water}

The response of piers in deep water is affected by hydrodynamic mass of a volume of water being forced to move with the pier. A reasonable estimate of the hydrodynamic added-mass is the mass of a circular cylinder of water of diameter equal to the pier width perpendicular to the direction of motion and length equal
to immersed depth11.7, $11.8,11.9$. This mass should be added to the pier mass when considering the seismic response.

\subsection{BRIDGES IN UNDESIRABLE LOCATIONS}

Whenever possible, the siting of bridges in locations where adverse ground conditions significantly increase seismic risk should be avoided. Such locations include sites crossing or immediately adjacent to an active fault, steep slopes with potential instability under earthquake conditions, and sands with a potential for liquefaction.

\subsubsection{Sites Across or Near Active Faults}

Bridges crossing or immediately adjacent to active faults may be subjected to large relative displacements of adjacent piers or supports as a result of surface fault expression. Although the probability of such occurrence at a given location during the design life of the bridge will be very low, the possibility should be considered in assessing a suitable structural type. A conservative design, particularly in terms of displacement capabilities should be adopted. Design of piers should aim at providing the maximum capacity possible, by use of extra confinement of plastic hinge zones. It will be advisable to provide an inner confined core (fig. 11-5) capable of supporting the structural dead weight on the assumption that the outer flexural confinement will have failed under an extreme event. This has the added advantage that under moderate, though not catastrophic inelastic displacements, the piers may be repaired by cutting out and replacing the buckled outer layer of steel. 
Relative merits of continuous vs. simple-span construction should be carefully evaluated. Although simplespans have the advantage of additional flexibility in comparison to continuous structures, difficulty will be experienced in ensuring the spans do not drop from supports. The additional redundancy of continuous monolithic pier/superstructure construction will tend to reduce the probability of total collapse.

Accelerographs of recent earthquakes indicate that vertical ground accelerations close to a fault can substantially exceed l.0g. This also supports the desirability of continuous monolithic construction.

Additional pier flexibility may be obtained by locating pile caps below ground surface to increase pier length.

It should be recognised that the purpose of design for such an extreme event will be to avoid, or at lease minimise, loss of life by reducing the probability of total collapse. After such an earthquake it is probable that the bridge would have to be demolished and replaced.

\subsubsection{Slopes with Instability Potential}

Many bridges are inevitably sited across steep-sided valleys. Detailed geotechnical investigations should be made to assess potential for slope instability under seismic attack. For major structures these investigations should include geological and geomorphic studies including expert study of aerial photographs, for evidence of bank movement under recent earthquakes, as well as material testing and extensive bore-hole and trenching investigations to check for unstable layers and vertical fissures. Particular attention should be paid to drainage to prevent infiltration of surface water and increased porewater pressures in potential failure regions. Special studies should be made to investigate the practicality of improving factors of safety against slope failure by such means as unloading the banks by removal of some top material. It may be advisable to site each abutment well back from the top of the slope, and tie back any intermediate pile caps located on the bank using rock anchors or other techniques.

\subsubsection{Liquefiable Foundations}

The assessment of liquefaction potential, and methods to reduce it, have been covered in section 4 .

There does not appear to be any viable method to design a bridge to remain serviceable if liquefaction occurs under one or more pier foundations. As liquefaction can occur at considerable distances from the epicentre, the factor of safety against liquefaction must therefore be high. In rare cases when the factor of safety is felt to be only marginally acceptable, design should aim to provide maximum feasible ductility capacity to avoid total catastrophic collapse. The arguments of section 11.4.1 indicate that increased ductility detailing and continuous monolithic construction will generally be appropriate.

\subsection{REFERENCES}

11.1 Troitsky, M.S., "Cable-stayed Bridges - Theory and Design", Crosby Lockwood, Staples, London, 1977.

11.2 Selberg, A., "Dampening Effects in Suspension Bridges", Publs. Int. Ass. Bridge Struct. Engng., 10, pp. 183-198, 1950.

11.3 Hjorth-Hansen, E., Sigbjörnsson, R. "Aerodynamic Stability of Box Girders for the Proposed Strömstein Bridge", Division of Structural Mechanics, The Norwegian Institute of Technology, University of Trondheim, Norway, Feb. 1975.

11.4 Biggs, J.M., "Introduction to Structural Dynamics", McGraw-Hill, New York, 1964, 34 lpp.

11.5 Gates, J.H., "Factors Considered in the Development of the California Seismic Design Criteria for Bridges". Applied Technology Council Workshop on the Research Needs of Seismic Problems Related to Bridges, San Diego, 1979, $21 \mathrm{pp}$.

11.6 Chen, M.C. and Penzien, J. "Soil Structures Interaction of Short Highway Bridges", Applied Technology Council Workshops on the Research Needs of Seismic Problems Related to Bridges, San Diego, 1979, 33pp.

11.7 Newmark, N.M. and Rosenblueth, E., "Fundamentals of Earthquake Engineering", Prentice-Hall International, N.J., 1971, 640pp.

11.8 Jacobsen, L.S., "Impulsive Hydrodynamics of Fluid Inside a Cylindrical Tank, and of Fluid Surrounding a Cylindrical Pier", Bull. Seism. Soc. Am. Vol. 39 No. 3, 1949, pp.189-204.

11.9 Levy, Wilkinson, "The Component Element Method in Dynamics", McGraw-Hill, Chapter 9, 1976. 